\title{
Cosmetic surgical procedures on the vulva and vagina - an overview
}

\author{
RAJESH PANICKER, THUNGA PANDURANGAN
}

\begin{abstract}
Cosmetic surgery is defined as any procedure involving a change in the appearance or aesthetics of a normal anatomy where there are no congenital or acquired pathologies. The procedures that can be included under female cosmetic genital surgery are the following: reduction labiaplasty, vaginoplasty, hymenoplasty, "G-Spot amplification", and miscellaneous.

Those who support these procedures could argue that women undergo such procedures as a matter of choice, whereas those opposed could argue that this choice is made because of society's fascination with physical appearance and feeling young. Prima facie these procedures appear to contradict the Hippocratic principle of "primum non nocere".

There has been an increase in the marketing and conduct of the above mentioned procedures. Practitioners need to be both sceptical and cautious while performing these surgeries. Patients requesting them need to be counseled regarding the lack of data supporting their efficacy, and the potential complications of the procedures.
\end{abstract}

Keywords: Cosmetic, aesthetics, ethics, labia, rejuvenation, counseling

\section{Introduction}

The term "cosmetic surgery" denotes any procedure involving a change in the appearance or aesthetics of a normal anatomy, where there are no congenital or acquired abnormalities. Distinct from this, reconstructive surgery with respect to gynaecology refers to surgery performed on abnormal female genitalia, such as constructing a normal length vagina for congenital vaginal agenesis /poorly formed vagina, incision of an imperforate hymen, or even surgery for pelvic organ prolapse. Gynaecologists routinely perform such surgeries as medically indicated procedures.

Cosmetic surgical procedures on the vulva and vagina, also called female genital cosmetic surgery (FGCS), have been popular since the 1990s, amongst Anglo-American women. However, in the last 10 years, the number of patients undergoing FGCS has shown an exponential rise globally. In fact, modification of the external genitalia has become one of the top 20 most frequently performed cosmetic surgeries (1). The number of labiaplasty procedures performed in the US went from 2,142 in 2011 to 12,756 in 2018 (2). Is this rise fuelled by insurance policies reimbursing these procedures? The answer is no, because most insurance companies do not reimburse cosmetic surgery as it is considered non-essential. If that is the case, why are these surgeries being performed in large numbers? Why are more and more patients opting for these surgeries? Why are physicians performing these surgeries? Are these procedures safe? How effective are these procedures? In this overview, we cover the common cosmetic surgeries being performed on the female genital tract, discuss them in the context of the issues mentioned above, and correlate them with available data

The American College of Obstetricians and Gynecologists remains sceptical and cautious about FGCS due to its risks and lack of scientific data (3). We concur, and believe that these procedures, as of date, cannot stand up to ethical scrutiny.

We have limited ourselves to discussing FGCS and this overview is not a comment on other types of cosmetic surgery. Some authors include genital mutilating surgeries such as female circumcision as part of FGCS. However, we have not included them in this discussion, as that is a topic by itself.

\section{Female genital cosmetic procedures}

The procedures included under FGCS (4) are described below.

\section{Labiaplasty}

Labiaplasty, which is the surgical reduction of the labia minora, is the most common procedure under the umbrella of FGCS, and its prevalence has increased over the past 10-15 years. Evaluating the appropriate use of labial reduction would need objective criteria to define labial hypertrophy. At present there are no standardised criteria for defining labial hypertrophy in order to 
establish legitimate use of this procedure. One study found that the width of the labia minora ranged between $3 \mathrm{~mm}$ and $45 \mathrm{~mm}$ (5), implying wide variation; and the study does not include variations in region and ethnicity. Moreover, an examination of labial tissue removed from girls who had undergone labial surgery showed that the labia minora are highly innervated along the entire free edge and have a microscopic structure that facilitates engorgement during sexual arousal (6). It follows, therefore, that labiaplasty can adversely affect sexual experience for a woman.

There are no randomised trials to show outcomes following labiaplasty. In one retrospective study there was a $91.6 \%$ satisfaction rate (7). However, the study was retrospective, had a low participation rate and an abnormally high satisfaction rate, and there were no specific criteria used for deciding to perform the procedure. In another study the perception of normal labia was evaluated amongst women with anatomically normal vaginas, using pre-labiaplasty and post-

labiaplasty images. The majority of the respondents picked the post-operative images as normal (8). This study would hardly be a long-term vindication for this procedure, and it brings out how the lay public's perception of normal and abnormal is blurred.

\section{Cosmetic vaginoplasty}

Cosmetic vaginoplasty traditionally refers to a procedure done to tighten the normal vaginal opening. The most common surgical procedure employed for this purpose is the posterior vaginal wall repair (also called posterior colporrhaphy) with or without perineal tightening. Vaginal tightening has also been attempted using radiofrequency heat waves or laser on the vagina to induce fibrosis and resultant tightening. The combination of labiaplasty and cosmetic vaginoplasty is called "vaginal rejuvenation". This procedure is different from reconstructive surgery that is performed for a prolapsed vaginal wall or a lax vaginal outlet following repeated deliveries.

Does this procedure enhance vaginal sensitivity, as some proponents claim? There are no studies to substantiate this hypothesis. Does vaginal tightening enhance the sexual response in either the male or the female? Again, there is no evidence to confirm this hypothesis. Instead in one study, the reported rates of painful intercourse following posterior vaginal wall repair ranged between $13 \%$ and $20 \%(9,10)$.

\section{Hymenoplasty}

This most controversial of surgeries is a reconstruction or repair of a ruptured hymen. It is also called hymenorrhaphy. If hymenal remnants are small, a flap of vaginal skin from the posterior vaginal wall is approximated to the anterior wall as a band across the hymenal ring (11). An intact hymen is suggestive of virginity which has social, legal and religious implications. This surgery has no official sanction even though it is not governed by laws that criminalise female genital mutilation. Gender activists oppose this surgery since virginity is a concept that promotes a patriarchal mindset and discriminates against women.

\section{G-spot amplification}

G-spot amplification is a physician-administered treatment that claims to temporarily augment the sensitivity of the Grafenburg spot (G-spot) in sexually active women. In this procedure gel-based hyaluronic acid is injected into the labia majora, the labia minora and the anterior vaginal wall. Those who perform this surgical procedure claim that smoothening of the wrinkles and an increase in the surface area of the erogenous zones heighten the sexual response. Hyaluronic acid is not US FDA approved for vaginal use, and the American College of Obstetrics and Gynecology does not endorse it as effective or safe. In fact, a case has been reported of pulmonary embolism of hyaluronic acid following its use in the vagina (12).

\section{Miscellaneous procedures}

The other cosmetic procedures performed include liposuction of the mons pubis, either independently or in conjunction with abdominal liposuction. The claim is that reduction in the mons will improve the aesthetic look of the external genitalia.

Fat injections into the mons and the labia majora and minora have also been tried as attempts to circumvent the changes of aging. These procedures could lead to local infection and even scarring, and there is no evidence to show any long-term benefits.

\section{Ethical issues}

Gynaecologists' practice of FGCS raises complex ethical issues. These include adequacy of training and safety, conflict of interest, gender rights and the commercialisation of medicine by practitioners who perform surgeries only for profit (13). Those who support these surgeries could argue that this is a woman's choice; after all, women have a right to have body aesthetics which they perceive as being ideal for themselves. They could also argue that it is the patient who does not perceive her status as normal even though she may actually be normal. Having these surgical procedures would make her feel "more normal". This could be construed as an acceptable indication for a practitioner to carry out FGCS. Those opposed to these surgeries could counter this argument by stating that increased visual depiction of the female form on different multimedia platforms and the aggressive marketing of these surgeries have made women victims of society's fascination with physical appearance.

How do FGCS measure up to the four principles of biomedical 
ethics as described by Beauchamp and Childress? Let us take them one by one.

Autonomy: An individual should have the freedom to make a choice about his or her appearance; hence FGCS does satisfy the first criterion. However, if advertisements play a role in making the choice, it is condemnable. When adolescents approach physicians, or parents bring their adolescent wards, the physician should ensure that performance of FGCS before the age of majority is strictly avoided.

Beneficence: Whether the above surgeries are beneficial is debatable; in fact, there is no evidence that these procedures improve the anatomical or physiological functioning of the human body. The psychological benefit is nebulous, and to all purposes, insignificant $(14,15)$.

Maleficence: As detailed above, most of these surgeries can have unintended long-term consequences which could affect normal functions of the body. Prima facie these surgeries appear to contradict the Hippocratic principle of "primum non nocere".

Justice: Here there is ambiguity, since one has to consider issues of gender equality, personal choice and self-esteem, practitioners' remuneration, and short-term benefits versus long-term complications. The issue of gender equality could come up in the case of the "revirgination" procedure mentioned above, or if a woman requesting FGCS is advised against it and the counseling physician is male. On the whole, the available evidence points to FGCS having harmful longterm effects, but proponents of FGCS can claim that shortterm benefits could be an indication in their favour.

The answer to the question "Why are physicians performing these surgeries?" is also complicated. As the demand for these procedures goes up there is an increase in the supply of physicians willing to perform FGCS. Large corporate entities are also joining the bandwagon making these procedures extremely lucrative (16).

There are two more issues that need highlighting; one is lack of information and the other is misinformation.

In a study performed on the paediatric and adolescent age group, it was found that many parents and guardians came requesting FGCS because they believed that the child's vulva was abnormal in appearance, but in most of the cases, there was no abnormality present in the external genitalia (17). The authors of the study suggest counseling adolescents and their parents, and emphasising the concept of normality and diversity with respect to the anatomy and physiology of the vulva and vagina. Physicians and caregivers also need to be trained regarding the variations in external genitalia. It is also well established that medical students and residents have very poor knowledge of cosmetic surgery, especially its ethical aspects (18). Hence, there is reason to promote healthy discussions amongst students and residents about all aspects of FGCS.
Secondly, with reference to misinformation, there is a perception amongst the lay public that FGCS will enhance the sexual experience of the male and female partner. There is no evidence to substantiate this claim (15); in fact, there is evidence to the contrary. Operations on erogenous areas such as the labia and clitoris may cause damage to the vascular and nerve supply. This will have a negative impact on sexual satisfaction and pleasure (19).

Keeping these ethical issues in mind it appears easy to reject a request for performing such surgeries from a moral standpoint. However, there is a view that practitioners should make such decisions on an individual basis, after careful deliberation on all aspects with the stakeholders concerned (20).

\section{Conclusion}

There has been an increase in the marketing and performance of FGCS. These procedures are marketed as ways to enhance appearance or sexual gratification. However, there is little or no evidence to justify these procedures, especially on the grounds of enhanced sexual gratification. When a patient requests FGCS, the practitioner must delve into the underlying psychological reason for the request. A thorough physical examination is essential to exclude any anatomical abnormality requiring surgery. Thereafter, the patient's concern for the appearance of her external genitalia should be allayed by explaining the wide range in the appearance of external genitalia of a woman. Patients need to be counseled that there is no correlation between appearance and sexual gratification, and this is true for both the male and the female partner. They must also be informed about the surgeries' potential complications, including infection, altered sensation, painful intercourse, adhesions and scarring.

Practitioners themselves need training on how to respond to women who demand such cosmetic surgery. Sometimes outright rejection of a patient's request may prove counterproductive; instead, counseling regarding the lack of data supporting the efficacy of these procedures, and their potential complications, is likely to be more effective in allaying patients' concerns. Future research and deliberations must concentrate on studying all aspects of FGCS and in formulating ethical guidelines for practitioners.

\section{References}

1. Pauls RN, Rogers RG, Rardin CR. Should gynecologists provide cosmetic labiaplasty procedures? Am J Obstet Gynecol. 2014; 211 (3): 218-21.

2. American Society for Aesthetic Plastic Surgery. Cosmetic (Aesthetic) Surgery National Data Bank Statistics 2018[cited 2021 Feb 18] Available from: https://www.surgery.org/sites/default/files/ASAPSStats2018_0.pdf

3. ACOG committee opinion No378. Vaginal rejuvenation and cosmetic vaginal procedures. Obstet Gynecol. 2007 Sep; 110(3):737-8. DOI: 10.1097/01.AOG.0000263927.82639.9b

4. Cosmetic Surgery National Data Bank Statistics. American Society for Aesthetic Plastic Surgery; 2012[cited 2021 Feb 18]. Available from: https://www.surgery.org/media/statistics

5. Cao Y, Li Q, Zhou C, et al: Measurements of female genital appearance in Chinese adults seeking genital cosmetic surgery: a 
preliminary report from a gynecological center. Int Urogynecol J. 2015[cited 2021 Feb 18]; 26: 729-35. Available from: https:// link.springer.com/article/10.1007\%2Fs00192-014-2584-6

6. Schober J., Cooney T., Pfaff D., et al: Innervation of the labia minora of prepubertal girls. J Pediatr Adolesc Gynecol. 2010; 23: 352. DOI: 10.1016/j.jpag.2010.03.009

7. Goodman M.P., Placik O.J., Benson R.H., et al: A large multicenter outcome study of female genital plastic surgery. J Sex Med. 2010; 7: 1565. DOI: 10.1111/j.1743-6109.2009.01573.x

8. Skoda K, Oswald FE, Shorter L, Pedersen CL. Perceptions of Female Genitalia Following Labiaplasty. J Sex Res. 2020; 57(9); 0022-4499. DOI: 10.1080/00224499.2020.1808563

9. Helström L, Nilsson B. Impact of vaginal surgery on sexuality and quality of life in women with urinary incontinence or genital descensus. Acta Obstet. Gynecol Scand. 2005;84 (1):79-84. DOI: 10.1111/j.0001-6349.2005.00668.x

10. Lemack GE, Zimmern PE. Sexual function after vaginal surgery for stress incontinence: results of a mailed questionnaire. Urology. 2000;56 (2): 223-7. DOI: 10.1016/s0090-4295(00)00626-9.

11. Logmans A, Verhoeff A, Raap RB et al: Should doctors reconstruct the vaginal introitus of adolescent girls to mimic the virginal state? Who wants the procedure and why. BMJ. 1998;316:459-462.

12. Park HJ, Jung KH, Kim SY, Lee JH, Jeong JY, Kim JH. Hyaluronic acid pulmonary embolism: a critical consequence of an illegal cosmetic vaginal procedure. Thorax. $2010 \mathrm{Apr} ; 65(4): 360-1$.

13. Indman PD. Should the AAGL be involved in cosmetic surgery? J
Minim Invasive Gynecol, 2007 Mar-Apr;14(2):139-40. DOI: https:// doi.org/10.1016/j.jmig.2007.01.001

14. Sorice-Virk S, Li AY, Canales FL.; Furnas HJ. Comparison of patient symptomatology before and after labiaplasty. Plast Reconstr Surg. 2020 Sep; 146(3): 526-36. DOI: https://doi.org/10.1097/PRS. 0000000000007081

15. Shaw D, Lefebvre G, Bouchard C, Shapiro J. Blake J, Allen L, et al. Female genital cosmetic surgery. J Obstet Gynecol Can. 2013 Dec; 35(12):1108-12. DOI: 10.1111/aogs.12687.

16. Svensson E. The commercialization of plastic surgery. Aesthet Surg J., 2013 Sep;33(7):1065-68. DOI: 10.1177/1090820X13500049

17. Runacres SA, Wood PL. Cosmetic labiaplasty in an adolescent population. J Pediatr Adolesc Gynecol. 2016 Jun;29(3): 218-22. DOI: 10.1016/j.jpag.2015.09.010.

18. Fraser SJ, AI Youha S, Rasmussen PJ, Williams JG. Medical student perception of plastic surgery and the impact of mainstream media. Plastic Surg (Oakv). $2017 \quad$ Feb;25(1):48-53. Doi: $10.1177 / 2292550317694844$.

19. Minto CL, Liao LM, Woodhouse CR, Ransley PG, Creighton SM. The effect of clitoral surgery on sexual outcome in individuals who have intersex conditions with ambiguous genitalia: a cross sectional study. Lancet. 2003 Apr 12; 361(9365): 1252-57. Doi: 10.1016/S01406736(03)12980-7.

20. Liao LM, Creighton SM. Requests for cosmetic genitoplasty: how should healthcare providers respond? BMJ. 2007 May 26;334(7603): 1090-2.Doi:10.1136/bmj.39206.422269.BE. 